\title{
Editorial: acceptance criteria and editorial procedures for Optics Letters.
}

\author{
Zhang, Xi-Cheng; Andersen, Peter E.; Justus, Brian L.; Galtarossa, Andrea
}

Published in:

Optics Letters

Link to article, DOI:

10.1364/OL.39.000ED2

Publication date:

2014

Document Version

Publisher's PDF, also known as Version of record

Link back to DTU Orbit

Citation (APA):

Zhang, X-C., Andersen, P. E., Justus, B. L., \& Galtarossa, A. (2014). Editorial: acceptance criteria and editorial procedures for Optics Letters. Optics Letters, 39(17), ED2-ED3. https://doi.org/10.1364/OL.39.000ED2

\section{General rights}

Copyright and moral rights for the publications made accessible in the public portal are retained by the authors and/or other copyright owners and it is a condition of accessing publications that users recognise and abide by the legal requirements associated with these rights.

- Users may download and print one copy of any publication from the public portal for the purpose of private study or research.

- You may not further distribute the material or use it for any profit-making activity or commercial gain

- You may freely distribute the URL identifying the publication in the public portal

If you believe that this document breaches copyright please contact us providing details, and we will remove access to the work immediately and investigate your claim. 


\title{
Editorial: acceptance criteria and editorial procedures for Optics Letters
}

\author{
Xi-Cheng Zhang, ${ }^{1, *}$ Peter E. Andersen, ${ }^{2}$ Brian L. Justus, ${ }^{3}$ and Andrea Galtarossa ${ }^{4}$ \\ ${ }^{1}$ Optics Letters Editor-in-Chief; Institute of Optics, University of Rochester, New York, New York, USA \\ ${ }^{2}$ Optics Letters Deputy Editor; Department of Photonics Engineering, Technical University of Denmark, Kgs. Lyngby, Denmark \\ ${ }^{3}$ Optics Letters Deputy Editor; Optical Sciences Division, Naval Research Laboratory, Washington, DC, USA \\ ${ }^{4}$ Optics Letters Deputy Editor; Department of Information Engineering, University of Padova, Padova, Italy \\ *Corresponding author: xi-cheng.zhang@rochester.edu \\ Received August 13, 2014; \\ posted August 13, 2014 (Doc. ID 220977); published August 29, 2014 \\ Optics Letters Editors strive to provide timely reviews and decisions for authors while bringing top quality papers to \\ the optics community. The purpose of this editorial is to explain Optics Letters' acceptance criteria and editorial \\ procedures. Our hope is that greater transparency concerning the decision-making process will increase under- \\ standing as well as acceptance of our criteria and procedures. (c) 2014 Optical Society of America \\ OCIS codes: (000.1200) Announcements, awards, news, and organizational activities; (000.5360) Physics literature \\ and publications. \\ http://dx.doi.org/10.1364/OL.39.000ED2
}

As the editors of Optics Letters (OL), we thank our exceptional author, reviewer, and reader communities for your ongoing support of the journal. Because of you, we are fortunate that the number of submissions and published papers has steadily increased in recent years. These high-quality papers lay the foundation for a strong journal with a prestigious reputation in the optics and photonics community. In an effort to maintain and reinforce the reputation of OL, our editorial team has carefully monitored these trends and has made slight adjustments to our acceptance criteria. The purpose of this editorial is to provide transparency to the community and explain our acceptance criteria and editorial procedures. These criteria have been emphasized to all OL Topical Editors (TEs) in order to maintain a high degree of uniformity in the decision-making process for all topical areas covered in the journal.

There are several key criteria for acceptance in the journal. OL papers should be:

- In the field of optics and photonics;

- Letters, as defined by both the required four-page limit and reporting important, novel early results of work-in-progress; and

- In need of rapid publication.

In case any of these criteria are dubious, even if the content is technically correct, the manuscript is not appropriate for OL.

After submission, but prior to peer review, manuscripts undergo the following editorial reviews:

- Initial check for completion by OSA staff;

- Initial technical review by a Deputy Editor (DE); and

- Content evaluation by a TE to decide whether the manuscript should be sent out to peer review.

Manuscripts may not pass DE or TE editorial review due to the content being considered incremental, not meriting rapid publication, being outside the journal's topic scope, or having English language deficiencies. In these cases, the manuscript is not sent for review. These editorial reviews are important steps that allow us to avoid overusing our valuable reviewers and to provide authors with timely decisions.

Once a paper has passed TE review it follows the workflow below:

- TE solicits feedback from external reviewers and strives to receive two reviews for each paper.

- Reviewers provide TE with constructive comments and a recommendation on whether to publish the manuscript.

- TE evaluates the comments and makes a decision based on the reviews and his/her own technical insight.

- If needed, TEs may edit reviewer comments.

- TE delivers decision to authors through the peer review system.

Generally, TEs make decisions following these guidelines:

- Two in-depth positive reviews: Accept.

- Major revisions required: Reject.

- Two in-depth negative reviews: Reject.

- One negative review, one positive review: Editorial judgment used.

OL requires two positive reviews in order to accept a paper for publication. Minor revisions, whether optional or mandatory, refer to changes that can be made to the text or figures and do not require re-review. To ensure rapid publication, OL does not send revised papers back to the reviewers after the authors have responded to the peer review comments. Instead, OL TEs determine if the authors have sufficiently addressed any significant concerns that were raised. In a rare case, a TE may use the same reviewer(s) to comment on the revised manuscript.

Likewise, OL editors will reject papers that need major revisions, which could involve requiring more data or additional computational modeling or significant rewriting to improve the clarity of the paper. Such major revisions might normally rely on a follow-up opinion from the reviewers, but as mentioned above, OL restricts the use of re-review. Authors may still resubmit their work as a 
new manuscript to OL after making the required major revisions to address the reviewers' comments. The new submission should be accompanied by a cover letter or detailed response to the reviewers' comments and an indication of the revisions made in the revised manuscript so that all individuals involved in the review process can assess the changes. A marked version of the manuscript may also be provided.

In the case of contradicting recommendations from the reviewers, i.e., one negative report and one positive report, the TE will use best judgment to render a manuscript decision. Actually, the TE could reject the paper because it failed to receive two positive reviews, which is our requirement for acceptance. Or, the TE may choose to solicit additional peer review feedback in order to break the tie. It is important for authors to understand that the TE can reject a paper based on one negative review that provides sound arguments against publication, despite any positive comments from the second reviewer. If the paper is rejected with conflicting review reports, the TE will communicate the reason(s) for the rejection. More rarely, a TE could provide a second positive review, based on his expert opinion, and accept the paper.

It is also important for authors and reviewers to know that the editor has the authority to edit reviewers' comments when necessary. Edits may include cutting sensitive sentences, filtering inflammatory comments, correcting grammatical mistakes, etc. The editor will maintain the reviewer's original meaning as accurately as possible.
In this editorial we have outlined the general policies and rules for OL to allow authors some insight into the decision-making process; however, there might be rare circumstances where authors find it appropriate to appeal an editorial decision. Appeals are granted only to rectify errors and should not be considered a second chance. Authors should notify the OL staff at olmss@ osa.org to open the Appeal procedure in the peer review system. There will be an online form to complete to provide the DE and TE with the information needed to consider the appeal. When responding to the questions, authors should clearly explain their objections based on scientific and technical arguments. The TE may agree to send the manuscript for additional peer review, request to receive a revised manuscript, or decide to uphold the original decision.

The editorial team at Optics Letters believes that transparency regarding the decision-making criteria reinforces the reputation of the journal to the benefit of authors, reviewers, and readers, and, thus, the optics and photonics community as a whole. We welcome your comments and questions about the OL criteria described in this editorial. Please contact us at olmss@osa .org to send your feedback. Accordingly, we look forward to continuing to receive your high-quality, novel, and exciting results for rapid publication. Thank you for your ongoing support of Optics Letters.

Xi-Cheng Zhang, Editor-in-Chief Peter E. Andersen, Deputy Editor Brian L. Justus, Deputy Editor Andrea Galtarossa, Deputy Editor 